\section{A Slow Growing Mass of Hard Palate: Schwannoma-Case Report}

\section{Journal of}

Clinical \& Medical Case Reports

\author{
Mehmet Karataş ${ }^{1 *}$, Yasin Sarıkaya ${ }^{1}$, Sedat Doğan ${ }^{1}$ \\ İbrahim Halil Erdoğdu ${ }^{2}$, Haci Taner Bulut ${ }^{3}$ and \\ Şeyho Cem Yücetaş ${ }^{4}$
}

Hard palate; Intraoral approach

\begin{abstract}
Schwannomas or neurilemmomas are infrequent, benign, epineurium-encapsulated, slow-growing, solitary tumors of ectodermal origin derived from Schwann cells of the nerve sheath. They can arise from any cranial, peripheral, or autonomic nerve that contains Schwann cells. They present as slow growing painless swelling in the oral cavity or head and neck region. Approximately $25-45 \%$ of all Schwannomas are seen head and neck region and $80 \%$ of which arises from vestibulocochlear nerve and found rarely in oral cavity, about $1 \%$. We report a 36 year-old-female complaining about a painless, slow-growing mass of the hard palate. It was excised intraorally and histopathologically diagnosed as Schwannoma.
\end{abstract}

\section{Introduction}

Schwannomas or neurilemmomas are infrequent, benign, epineurium-encapsulated, slow-growing, solitary tumors of ectodermal origin derived from Schwann cells of the nerve sheath [1]. The first description of this type of tumor was made by Verocay who named it as neuronoma in 1907 than in 1935, Stout called it as neurilemmoma $[1,2]$. They can arise from any cranial, peripheral, or autonomic nerve that contains Schwann cells. They present as slow growing painless swelling in the oral cavity or head and neck region and are rare encountered in clinical practice. Approximately $25-45 \%$ of all schwannomas are seen head and neck region and $80 \%$ of which arises from vestibulocochlear nerve and found rarely in oral cavity, about $1 \%$ [3-7]. Tongue, palate, buccalmucousa, lip, and gingivaare, in descending order, the most common sites for intraoral Schwannomas $[8,9]$. These tumors usually arise in $3^{\text {rd }}$ and $4^{\text {th }}$ decades but were also reported in early childhood [10-13]. They are equally distributed in males and females [14,15]. These submucosal lesions must be differentiated from other benign lesions that also appear in the same regions. Anti-S100 protein is the most widely used antibody for the identification of this neoplasm. Herein we report a 36 yearold-female complaining about with a painless, slow-growing mass of the hard palate. It was excised intraorally and histopathologically diagnosed as Schwannoma.

\section{Case Report}

A 36 year-old-female presented to our clinic with a painless, slow-growing mass at right side of the hard palate for three years. There was no facial pain and numbness or epistaxis. She had undergone root canal therapy for teeth caries three years ago and the mass has emerged around the treated teeth. Physical exam showed pink, firm, painless, $3 \times 5 \mathrm{~cm}$ in size, smooth mass at the right side of the hard palate (Figure 1). There was no tenderness or ulceration. Haematologic and biochemical findings were normal. T2-weighted sagittal maxillofacial magnetic resonance imaging (MRI) displayed homogen, hyperintense, $2 \times 4 \mathrm{~cm}$ in size solid lesion of hard palate
${ }^{\prime}$ Department of Otorhinolaryngology, Adiyaman University Medical School, Adiyaman, Turkey

${ }^{2}$ Department of Pathology, Adiyaman University Medical School, Adlyaman, Turkey

${ }^{3}$ Department of Radiology, Adivaman University Medical School, Adlyaman, Turkey

${ }^{4}$ Department of Neurosurgery, Adlyaman University Medical School, Adiyaman, Turkey

*Address for Correspondence:

MehmetKarataş, Assistant Professor, Department of Otorhinolaryngology, Adıyaman University Faculty of Medicine, Adıyaman, Turkey, Tel: +9

Submission: 09 March 2015

Accepted: 17 March 2015

Published: 21 March 2015

Reviewed \& Approved by: Dr. Ayman G. Mustafa, Assistant Professor of Anatomy, Jordan University of Science and Technology, Jordan

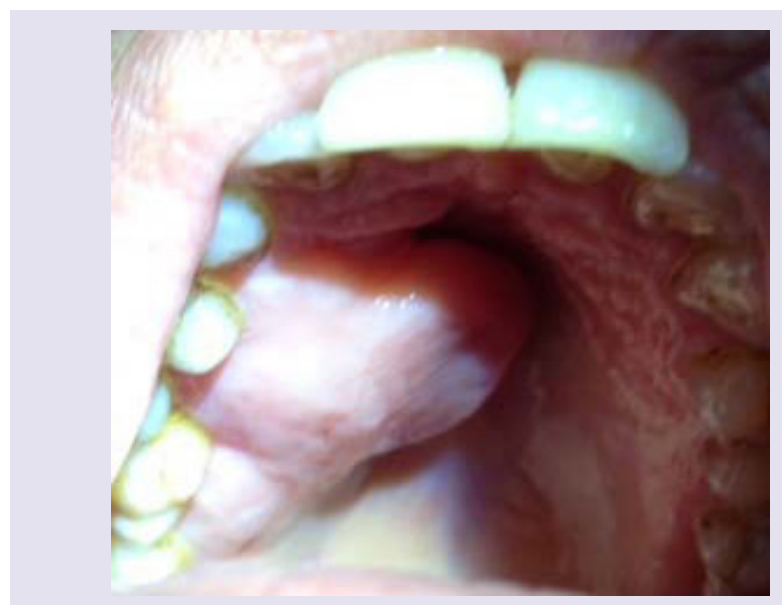

Figure 1: Pink, smooth mass without bone erosion at right side of hard palate.

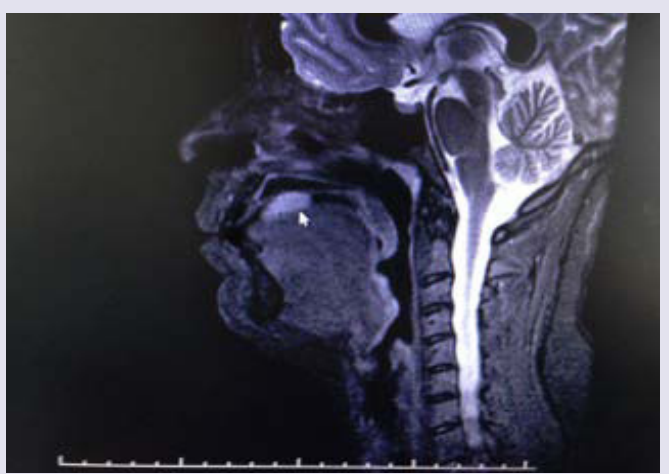

Figure 2: Hyperintense mass on sagittal paranasal MRI (arrow) 053270484 41; E-mail: mehmetkaratas78@gmail.com 
with regular border (Figure 2). Axial maxillofacial non-enhanced computed tomography (CT) revealed a triangular-shaped, $3 \times 5 \mathrm{~cm}$ in size mass which had soft-tissue density with regular border but without bone erosion at the right side of the hard palate (Figure 3).

Under general anesthesia the mass was completely excised via transoral route. Meticulous bleeding control was performed and then surgical area was allowed to heal by secondary intention. Postoperative period was uneventful.

Microscopically, it was an encapsulated tumour and there were Antoni Aareas which are composed of areas of hypercellular spindled cells arranged in palisades, Antoni B areas that consist of edematous, myxoid-appearing stroma with few spindled cells and Verocay bodies that are central acellular eosinophilic around which Antoni A areas form a palisaded arrangement (Figure 4). Immunohistochemical staining was positive for S-100 protein and vimentin (Figures 5 and 6). In the light of these findings it was diagnosed as Schwannoma. There was no recurrence after a 18-month period follow up (Figure 7).

\section{Discussion}

Schwannomas or neurilemmomas are infrequent, benign, epineurium-encapsulated, slow-growing, solitary tumors of

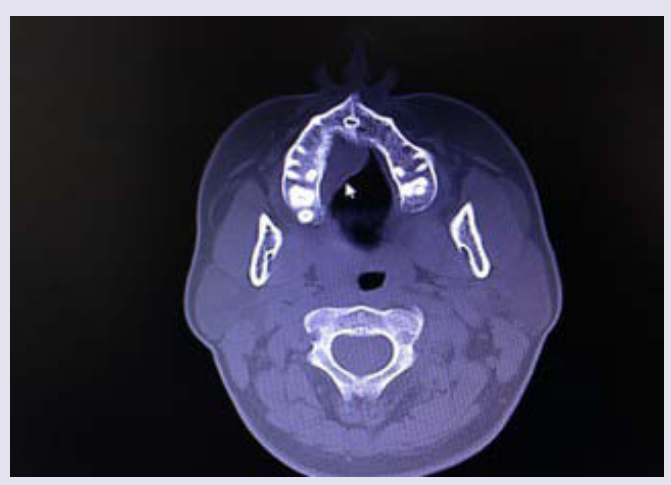

Figure 3: Triangular-shaped soft tissue at right side of hard palate on axial paranasal CT (arrow).

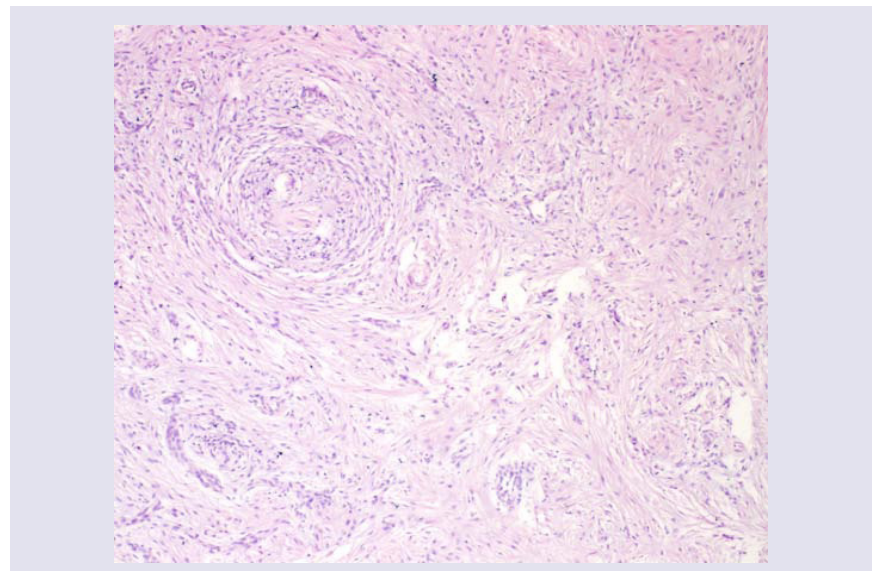

Figure 4: Staining with hematoxylen and eosin: hypocellular Antoni B area around hypercellular Antoni $A$ area (left superior). Antoni $A$ areas are composed of palisading spindled cells (H\&E X10).

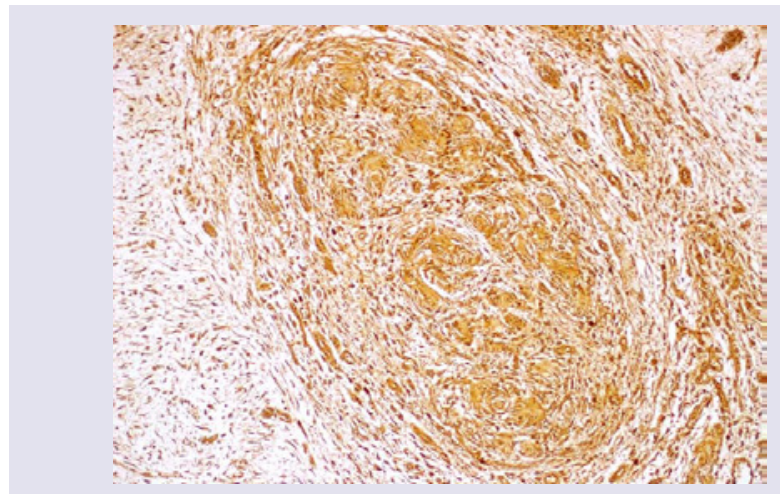

Figure 5: Immunohistochemical statining with Vimentin: hypocellular Anton $B$ area (left-inferior part) adjacent to a hypercellular Antoni $A$ area (middle part). Antoni $A$ areas are composed of palisading spindled cells, also known as Verocay bodies (Vimentin X10).

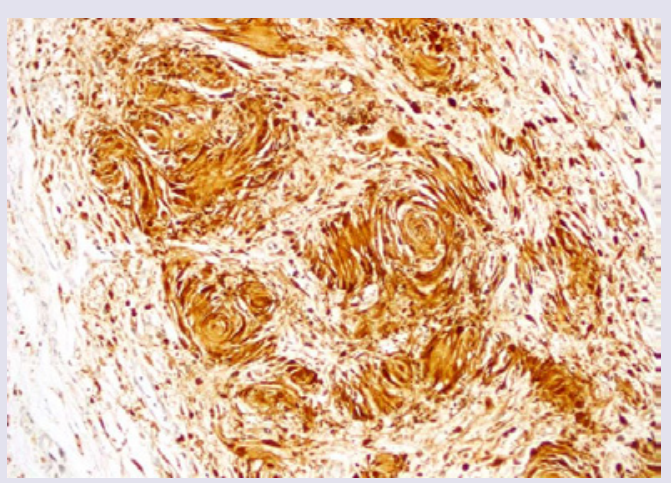

Figure 6: Immunohistochemical statining with S-100: hypercellular Anton $A$ area (middle part) and hypocellular Antoni B area (left-inferior and rightsuperior) (S-100 X20).

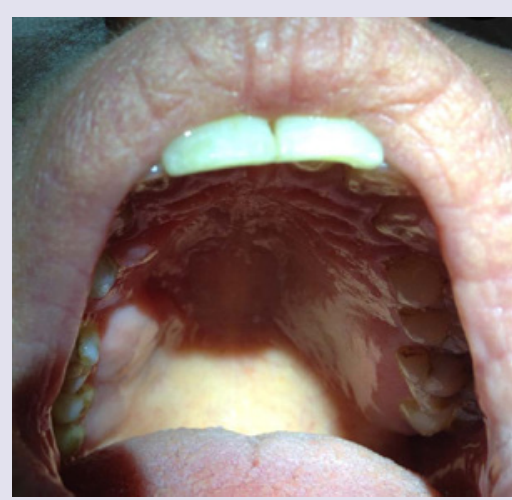

Figure 7: Appearance of hard palate at postoperative 1st year

ectodermal origin, derived from Schwann cells of the nerve sheath and usually arise in $3^{\text {rd }}$ and $4^{\text {th }}$ decades but were also reported in early childhood [1,10-13]. Etiology of these tumours is still unknown [3]. They have genetic basis. They are equally distributed in males and females [14,15]. Tongue, palate, buccal mucousa, lip, and gingivaare, in descending order, the most common sites for intraoral Schwannomas $[8,9]$.

Clinical differential diagnosis of intraoral Schwannoma includes 
fibroma, neurofibroma, lipoma, mucosele, granular cell tumour, traumatic fibroma, salivary gland tumours and malignant lesions such as squamous cell carcinomas and sarcomas [16]. Head and neck Schwannomas are usually manifested as a solitary, slow-growing, painless mass. They mainly occur in the peripheral nerves and also sometimes in the intraspinal and inner ear location where it is called acoustic schwannoma arising from the eighth cranial nerve. Since the optic and olfactory cranial nerves lack sheets which contain schwann cells, they are not potential sites for schwannomas. Depending on the location of the tumor and its mass effect or nerve involvement, patients may have symptoms like pain, hoarseness, dysphagia, cranial nerve neuropathies, and even Horner syndrome [17]. Our patient did not suffer from neither of these symptoms but complained only of a painless and slow-growing mass.

MRI is usually the first choice of imaging modalities and these tumours appear as sharply circumscribed, fusiform, round, or oval masses. Schwannomas isointense to muscle on T1-weighted images and homogeneously hyperintense on T2-weighted images. Our patient had homogen, hyperintense mass with regular borderon T2 weighed MRI. CT usually reveals a sharply circumscribed, markedly enhancing, soft tissue mass without bone erosion. In terms of defining soft tissue tumors MRI is superior but CT provides better resolution of bone erosion. However, Schwannomas can erode bone by pressure, bony erosion is not a criterion for malignancy [18]. The present case had triangular-shaped mass with soft tissue density and no bone erosion.

Due to Schwannoma's rarity and nonspecific clinical presentation, its diagnosis is carried out with histopathologic and immunohistochemical confirmation. It is an encapsulated tumour and there are Antoni Aareas which are composed of areas of hypercellular spindled cells arranged in palisades, Antoni B areas that consist of edematous, myxoid-appearing stroma with few spindled cells and Verocay bodies that are central acellular eosinophilic around which Antoni A areas form a palisaded arrangement $[17,19]$. Immunohistostaining commonly displays positivity for Leu-7 antigen, S-100, vimentin, and glial fibrillary acidic protein and supports the Schwann cell origin of these tumors [20]. The histological differential diagnosis includes other neural origin lesions, which could be neurofibroma and neuroma, or muscular or fibroblastic origin tumour [21-23].

They are benign encapsulated tumors attached to the nerves where they arise in such a way that they can be easily removed without damaging the involved nerve but the other peripheral nerve sheath tumor, a non-capsulated tumor known as neurofibroma, has deeper connection to the involved nerve making it difficult to surgically remove [24]. Malign Schwannomas comprise 5\% of all soft tissue sarcomas and 9-14\% of them are seen in head and neck region [25]. Malign schwannomas are rarely seen and more often develop in association with von Recklinghausen's disease [26].

Because of their benign nature, complete surgical excision which can range from simple excision under local anesthesia to a more extensive facial degloving approach with particular attention to preservation of the originating nerve, if encountered, is the treatment of choice [8]. Local recurrence has not been reported with complete surgical excision of intraoral schwannomas [27]. Endoscopic approach can be performed in properly selected cases. In the literature there are no reported cases of recurrence.

\section{Conclusion}

Schwannomas, slow-growing benign tumours with unknown etiology, are seen relatively rare in intraoral cavity, especially on palatal region. Clinical diagnosis of them is difficult so that histopathological diagnosis is needed. This submucosal lesion should be distinguished from other pathologies of oral cavity. It should be kept in mind that a slow-growing, well circumscribed, painless, nontender mass of hard palate can be a Schwannoma. Treatment is complete surgical excision and prognosis is well with no reported recurrence.

\section{References}

1. Enzinger FM, Weiss SW (1995) Soft tissue tumors. 3rd ed. St Louis (MO): Mosby-Year Book Inc, p. 821-888.

2. Salla JT, Johann AC, Garcia BG, Aguiar MC, Mesquita RA (2009) Retrospective analysis of oral peripheral nerve sheath tumors in Brazilians. Braz Oral Res 23: 43-48.

3. López-Carriches C, Baca-Pérez-Bryan R, Montalvo-Montero S (2009) Schwannoma located in the palate: clinical case and lit-erature review. Med Oral Patol Oral Cir Bucal 14: e465-e468.

4. Lollar KW, Pollak N, Liess BD, Miick R, Zitsch RP 3rd (2010) Schwannoma of the hard palate. Am J Otolaryngol 31: 139-140.

5. Amirchaghmaghi M, Salehinejad J, Basirat M, Delavarian Z, Javadzadeh A, et al. (2010) Gingival ancient schwannoma: Review of literature and a case report. J Applied Sci 10: 3137-3140.

6. Isildak H, Yilmaz M, Ibrahimov M, Aslan M, Karaman E, et al. (2010) Schwannoma of the hard palate. J Craniofac Surg 21: 276-278.

7. Rahpeyma A, Jafarian AH, Khaje Ahmadi S, Sarabadani J (2012) A schwannoma of the soft palate in a child: histological and immunehistochemical features and surgical method. Iran J otorhinolaryngol 24: 95-99.

8. Berlucchi M, Piazza C, Blanzuoli L, Battaglia G, Nicolai P (2000) Schwannoma of the nasal septum: a case report with review of the literature. Eur Arch Otorhinolaryngol 257: 402-405.

9. Arda HN, Akdogan O, Ardave N, Sarikaya Y (2003) An unusual site for an intraoral schwannoma: A case report. Am J Otolaryngol 24: 348-350.

10. Cunningham LL Jr, Warner MR (2003) Schwannoima of vagus nerve first diagnosed as a parotid tumor. J Oral Maxillofac Surg 61: 141-144.

11. Cherrik HM, Eversole LR (1971) Benign neural sheath neoplasm of ora cavity: Report of thirty-seven cases. Oral Surg Oral Med Oral Pathol 32: $900-$ 909.

12. Shafer WG, Levy BM, Hine MG (1993) A text book of oral pathology, $4^{\text {th }}$ edition, WB Saunders \& Co., Philadelphia, 208-210.

13. Regezi and Sciubba (1993) Oral pathology, clinical-pathologic correlations, $2^{\text {nd }}$ edition WB Saunders \& Co., Philadelphia, 221-225.

14. Pfeifle R, Baur DA, Paulino A, Helman J (2001) Schwannoma of the tongue: report of 2 cases. J Oral Maxillofac Surg 59: 802-804.

15. Leu YS, Chang KC (2002) Extracranial head and neck schwannomas: a review of 8 years experience. Acta Otolaryngol 122: 435-437.

16. Prasanna Kumar D, Meghashri K (2012) Schwannoma of the hard palate: a case report and review of literature. J Adv Oral Res 3: 24-29.

17. Zhang H, Cai C, Wang S, Liu H, Ye Y, et al. (2007) Extracranial head and neck schwannomas: a clinical analysis of 33 patients. Laryngoscope 117: 278-281.

18. Younis RT, Gross CW, Lazar RH (1991) Schwannomas of the paranasal sinuses: Case report and clinicopathologic analysis. Arch Otolaryngol Head Neck Surg 117: 677-680. 
Citation: Karataş M, Sarıkaya Y, Doğan S, Erdoğdu ï, Bulut HT, et al. A Slow Growing Mass of Hard Palate: Schwannoma-Case Report. J Clin Med Case Reports. 2015;2(1): 4.

ISSN: $2332-4120$

19. Amir R, Altman KW, Zaheer S (2002) Neurilemmoma of the hard palate. J Oral Maxillofac Surg 60: 1069-1071.

20. López JI, Ballestin C (1993) Intraoral schwannoma. A clinicopathologic and immunohistochemical study of nine cases. Arch Anat Cytol Pathol 41: 18-23.

21. Martins MD, Anunciato de Jesus L, Fernandes KP, Bussadori KS, Taghloub AS, et al. (2009) Intra-oral schwannoma: case report and literature review. Indian J Dent Res 20: 121-125.

22. Das Gupta TK, Brasfield RD, Strong EW, Hadju SI (1969) Benign solitary Schwannomas (neurilemmomas). Cancer 24: 355-366.

23. Chrysomali E, Papanicolaou SI, Dekker NP, Regezi JA (1997) Benign neural tumors of the oral cavity. Oral Surg Oral Med Oral Pathol Oral Radiol Endod 84: $381-390$
24. Pagaro PM, Patil T, Chaudhari PK, Buch A (2013) Neurilemmoma of nose. Med J Dr. DY Patil University 6: 452-454

25. Colreavy MP, Lacy PD, Hughes J, Bouchier-Hayes D, Brennan P, et al. (2000) Head and neck schwannomas--a 10 year review. J Laryngol Otol 114 119-124

26. Mannan AA, Singh MK, Bahadur S, Hatimota P, Sharma MC (2003) Solitary malignant schwannoma of the nasal cavity and paranasal sinuses: report of two rare cases. Ear Nose Throat J 82: 634-636.

27. Jones JA, McWilliam LJ (1987) Intraoral neurilemmoma (schwannoma): an unusual palatal swelling. Oral Surg Oral Med Oral Pathol 63: 351-353. 